\title{
ESTIMATION OF TRANSPORT ACCESSIBILITY IN CASE OF RATIONAL TRANSPORT HUB LOCATION
}

\author{
Alexander ROSSOLOV ${ }^{1}$, Vitalii NAUMOV ${ }^{2}$, Nadezhda POPOVA ${ }^{3}$, \\ Ekaterina VAKULENKO ${ }^{4}$, Olena LEVCHENKO ${ }^{5}$ \\ ${ }^{1,4}$ Dept of Transport Systems and Logistics, O. M. Beketov National University of Urban Economy in Kharkiv, Ukraine \\ ${ }^{2}$ Dept of Transport Systems, Cracow University of Technology, Poland \\ ${ }^{3}$ Dept of Marketing and Trading Business, Kyiv National University of Trade and Economics, Ukraine \\ ${ }^{5}$ Dept of Traffic Control and Road Safety, Kharkiv National Automobile and Highway University, Ukraine
}

Submitted 24 March 2019; resubmitted 4 September 2019, 12 November 2019; accepted 8 February 2020

\begin{abstract}
The public transit accessibility has become an important attribute of social and economic activity of contemporary society. The shift to the sustainable paradigm of the current cities' development has made public transport the basic mean for population travels execution. The spatial character of the travels in the megapolises supposes its implementation with the transfers. This may result in the travel time increase if the transport hubs are designed or located inefficiently. In some cases, the transport hub locations do not reflect the current demand for public transport services and require the fulfilment of the infrastructure measures. The paper presents the Hub Location Problem (HLP) solving in the case of rapid transit and trolleybus lines interaction. It has been proposed the combined criterion for the HLP solving based on the two-dimensional coordinate system with the estimation of passenger walk turnover. The simulation procedure to estimate the transport hub relocation has been made in the PTV VISUM software in the case of the Industrial District of Kharkiv City (Ukraine). The results of the economic effect available from the transport hub rational location have been estimated.
\end{abstract}

Keywords: transport accessibility, transport hub, public transport stops, O-D matrix, transit network modelling.

\section{Introduction}

The travels are one of the common activities that a city's inhabitants undertake. Even though travels are made because of different reasons, the idea behind of all them is usually to cover a certain distance at the lowest cost and as fast as possible (Murray 2003). In this case, the transport accessibility plays a major role in forming the character of transportation results and acts as the main "product" of a transport system (Biosca et al. 2013). It acts as a new paradigm in the major construction plans of contemporary cities (Coppola, Nuzzolo 2011). From the point of view of its practical application, the efficiency of the public transport functioning is deduced by taking into account the time, trip price and infrastructure aspects (Yatskiv et al. 2017). All these transport system attributes reflect technological, technical and economic sides of the transportation process. Among them, technological and technical sides are the most important and significant, making the direct influence on the economic field. Nowadays, the spatial parameters of the transport process play a major role, especially for persons with disabilities and reduced mobility (Zając 2016). The transport designers should pay attention not only to decreasing travel distances but also even to such detailed parameters as level changes between the vehicles and platforms, terminal design (walk time expenditures) and interior vehicle design (Steinfeld 2010). Transport accessibility has to be estimated and guaranteed for all passengers, including people with physical disabilities, faced with real challenges every day when public transport is used (Azenkot et al. 2011).

\section{Literature review}

The public transport accessibility, e.g., Zając (2016), can be improved by upgrading transport vehicles with electric ramps and special push buttons. Besides that, the point to be noted is to improve the accessibility of the platforms, to facilitate easy access to route vehicles, and to modernize the large-scale infrastructure facilities (it means the

*Corresponding author. E-mail:vnaumov@pk.edu.pl 
technical improvement). Moreover, the Internet and big data availability allow to implement the crowdsourcing paradigm in the public transport system, for example, to accommodate the location of bus stops for blind people (Hara et al. 2015).

Without doubt, all these measures guarantee the achievement of the specified target, namely, an increase of public transport accessibility. However, the above-stated approaches are aimed only at technical development and do not take technological parameters into account. The availability of these factors provides a significant effect on technical measures implementation. This implies deploying the macro view approach, which means forming and coordinating a transport system based on physical concentration of people, services and economic activities (Rode et al. 2017). The general approach to determining the accessibility indicators generates two functions. The first function represents the opportunities that are to be achieved in some transport zone. The second one reflects the efforts, time expenditures or costs to reach the required opportunities (Spiekermann et al. 2015). According to this, transportation engineers especially should concentrate their efforts on the second function and factors that directly influence on it. The special characteristics of current metropolitan areas such as huge spatial dwelling and labour diversification face the necessity of transit-oriented development implementation and rail-based accessibility (Pagliara, Papa 2011; Papa, Bertolini 2015).

The transport accessibility is taken to mean a social equality and must be identical for people with different physical abilities (Bocarejo, Oviedo 2012). It is intimately connected with city inhabitants' work activity forming by that the attraction of the workplaces and resulting in the economic development of the city area. The high correlation has been specified between the transport accessibility to jobs and transportation costs that each citizen is willing to incur regarding to his purchasing power (Bocarejo, Oviedo 2012). This correlation points at the necessity of the local authorities to carry out the rational policy for public transport development and formation the rational tariff values making it payable.

The base of the transport accessibility is the design of the public transport network and its spatial characteristics. The public transit guarantees the high spatial accessibility level through the stops' density (Lohvinenko, Rossolov 2019), bus stops location (Alonso et al. 2011) and transit nodes (hubs) design attributes (Groenendijk et al. 2018). The high density of the public transport stops forms the higher transport accessibility through a walk time decrease. However, the rise of the vehicles dwell time at the public transport stops, for example, in the case of the transport bays usage may increase the travel time. Under such conditions, the total travel time gets bigger and the transport accessibility reduces (Lohvinenko, Rossolov 2019). This may cause the incorrect measures in public transport stops density reduction. The solution approach is to reduce the dwell time by locking the bays. This guarantees the high walk accessibility of the public transport lines to be very important for senior citizens and people with disabilities and forms the general transport accessibility with high level.

The transport accessibility is inextricably connected with land use components (Geurs, Van Wee 2004; Cordera et al. 2017), to characterize the spatial connections between households, jobs, shops, etc., and transport infrastructure elements. Herewith, the problem of transport accessibility increase within the framework of the rational transport hubs location deals with two groups of measures, namely: the infrastructure-based measures and the location-based measures (Geurs, Van Wee 2004). This shows the importance of the Hub Location Problem (HLP) during the perception of the transport accessibility by passengers and its actual value estimation by transport engineers.

The transport hub in frame of the transit system carries out the connective functions between different modes of public transport and is characterized by big numbers of the functional connections (Gelareh 2008). In that context, the HLP has the optimization nature and may be fulfilled as hubs median characteristics determination (Campbell 1996) or mixed integer programming tools (Campbell 1994; Nickel et al. 2001; Gelareh, Nickel 2011). In the furtherance of this goal from the point of $p$-hub median problem the general cost is considered as the optimization value to be formed taking into account the standard cost per unit transportation from location $i$ to location $j$, the flow of passengers (goods) from location $i$ to location $j$ and the fraction of flow from location (origin) $i$ to location (destination) $j$ that is routed via hubs at locations $k$ (Campbell 1996). Through this process, the transportation costs variation is achieved by change of the location $k$. If the standard cost per unit transportation component is replaced with transportation distance, the objective function will take the form of the total transport turnover to be widely-used as criterion for solving the routing problems or distribution centers location problems (Chi et al. 2019). A single HLP is successfully solved by the transportation cost or the turnover value optimization (Campbell 1996; Ernst, Krishnamoorthy 1999).

In this case, the usage of transport turnover value as an objective function may be perfectly acceptable for solving of the research problem and may be apply practically. When the object size increases the alternative choice numbers of the hub location will raise that requires the usage more powerful optimization tools (Campbell 1994; Nickel et al. 2001; Gelareh, Nickel 2011). Furthermore, the model adaptation to the real research object requires more precise mathematical description of the transport process elements. In addition, this complicates the procedure of the optimal transport hub location determination (Gelareh, 2008; Gelareh, Nickel 2011).

The literature analysis revealed that in the case of a single HLP solving the criterion of minimum general transportation costs or turnover on the network is implemented. The problem has the optimization character and the standard optimization procedures are applicable for 
small areas. The model of the transport network for HLP is presented as the graph that reflects the general character of two-dimensional rectangular systems (Campbell 1996; Gelareh 2008). This gives the opportunity to form the twodimensional coordinates system to optimize the transport hub location for public transit network.

\section{Research problem statement}

The public transport accessibility is a comprehensive concept that includes a list of the transport indices such as density of bus (tram, trolleybus, subway) stops in the case of population density (Saghapour et al. 2016), the development level of the city's public network in the transport area (Yu et al. 2012), walk time to the nearest station (Iacono et al. 2010) and etc. All these parameters reflect some specific aspects of the transportation process and travels realization as a consequence. As usual, each travel can be measured using the general cost of taking it, change in passenger fatigue or trip time (Vuchic 1999). Monetary valuation, which has a great advantage due to universality and easy perception of its results, is not a good fit for the estimation of the transportation process outcomes. This means the passenger financial losses rather than rolling stock exploitation. In this case, it is important to remember that the public transport plays, first at all, a social role and has a differing financial paradigm to other branches of the economy. Besides, majority of European cities already have used the horizontal fare payment system, which levels the influence of the trips number within one travel on general cost.

The second criterion mentioned above is the change in passenger fatigue. It is rather difficult to be utilized for the estimation for big passenger number. Usually the passenger fatigue criterion is used to evaluate the quality of the direct transportation process in the vehicle for small group of passengers (Kopytkov et al. 2018). Thus, according to this, it has been proposed to use the total time expenditures as the criterion for assessment the public transport accessibility. It has the following mathematical formula:

$$
T E=\sum_{i=1}^{Z} \sum_{j=1}^{Z} t_{i j} \cdot d_{i j},
$$

where: $T E$ is total travel time expenditures in the peakload period [min-pass]; $t_{i j}$ is the number of travels between $i$-th and $j$-th transport zones [pass]; $d_{i j}$ is duration of time for travel execution between $i$-th and $j$-th transport zones [min]; $Z$ is the number of transport zones.

The formula - Equation (1) - reflects the general statement for public transport system, but in the case of transport accessibility estimation, the components within the research object are to be pointed:

$$
d_{i j}=\left\{d_{q w}, I_{m}, m, \rho_{s}, l_{H}\right\},
$$

where: $d_{q w}$ is duration of the travel between public transport stops $q$ and $w$ [min]; $I_{m}$ is headway on the $m$-th route of the public transport [min]; $m$ is the average number of alternative routes that can be used between $q$ and $w$ public transport stops; $\rho_{s}$ is density of the public transport stops [units $/ \mathrm{km}^{2}$ ]; $l_{H}$ is the transfer distance stipulated by hub location $[\mathrm{km}]$.

In turn, the number of travels $t_{i j}$ from Equation (1), usually, is represented by Origin-Destination (O-D) matrix reflecting the demand for a city public network service. In the research, it has been proposed to apply the equal probability approach for O-D matrix calculation (Rossolov 2016). This allow to define the trip volume based upon the origin and destination probabilities:

$$
t_{i j}=p_{i} \cdot p_{j} \cdot Q_{p-h},
$$

where: $p_{i}$ is the probability of origin from $i$-th transport zone; $p_{j}$ is the probability of destination to $j$-th transport zone; $Q_{p-h}$ is the total number of passengers to be serviced within peak-hours period [pass].

The probabilities of origin or destination have been calculated based on transport zones origin and destination data (Rossolov 2016):

$$
\begin{aligned}
& p_{i}=\frac{O_{i}}{Q_{p-h}}, i \in[1 ; Z] ; \\
& p_{j}=\frac{D_{j}}{Q_{p-h}}, j \in[1 ; Z],
\end{aligned}
$$

where: $O$ is the number of origin passengers for $i$-th transport zone within peak-hours period [pass]; $D$ is the number of destination passengers for $j$-th transport zone within peak-hours period [pass].

This method of O-D matrices calculation allows to determine the intra zone trips instead of gravity-based model. Moreover, this method is easily applicable for small areas because for such objects the influence of distance between transport zones on travel values is not very high.

According to above mentioned, the study is aimed at determining rational transport hub location. It implies the minimization of total time expenditures for travel, especially for walking transfers when a change of transport mode takes place.

\section{Mathematical formalization of the object under research}

Considering the urban transportation system as a range of services, it must be described by specific parameters, which mostly reflect the spatial and objective attributes of the public transport network. Among all possible methods of modelling the spatial structure of the transport network, the most used approaches are based on two-dimensional coordinates systems. Despite some simplification, a flat interpretation has a big list of advantages among which are the most important: precise location of each transport system object, unique description of all transport system attributes and easy big data processing. According to this, most current transportation planning software is made using two-dimensional coordinates systems. The PTV VISUM is one such, which allows to simulate the transport 
system functioning using the standard attributes (https:// www.ptvgroup.com/en/solutions/products/ptv-visum): nodes (crossroads), links (streets), public transport stops, route variants (lines), transport zones and etc. Its spatial location is defined by $x$ and $y$ coordinates. Thus, in the frame of current research objectives the two-dimensional coordinates data gives large number of opportunities. It may be achieved the spatial optimization of the transport infrastructure elements, which, as result, increases the efficiency of passengers' demand for service by public transport. An increase of transport system accessibility will be obtained as a final dividend.

Current city public transport systems consist of several modes of transport, making them more flexible, efficient and reliable. Rational routing, timetabling, vehicle capacity determination and assessment of general transport possibilities enable transport system efficiency and accessibility. However, all these operations characterize the complexity of engineering measures at the middle level. The deeper functional level supposes infrastructural changes, such as city hub relocation, opening the new ones and abolishing the existing ones. In a multi-modal public system, this becomes an urgent and extremely important endeavour. The size of present-day metropolises forces the passenger to transfer between several modes of public transport within the one travel, for example, from home to the workplace. Under such conditions, not only does timetable coordination reduce passenger time expenditures, but minimization of walk transfer distance when changing transport modes is also of great importance. These measures must be executed strongly on the basis of information about travel distribution throughout the city territory. Such information is usually formed in an O-D matrix. The economic proportions changing between the city districts find their reflection in modification of travels taken. That in turn forces necessary adjustment to the transport infrastructure. According to this, the transfer distance stipulated by hub location can be defined using Pythagorean theorem in the two-dimensional rectangular systems:

$$
l_{H}=\sqrt{\left(x_{s}-x_{H}\right)^{2}+\left(y_{s}-y_{H}\right)^{2}},
$$

where: $x_{H}, x_{s}$ are accordingly, $x$ location coordinates of transport hub and public transport stop servicing $t_{q w} ; y_{H}$, $y_{s}$ are accordingly, $y$ location coordinates of transport hub and public transport stop servicing $t_{q w}$

In this case, the O-D matrix direct influences on rational hub location. This means that the optimal location will be obtained under fulfilment of condition $l_{H} \rightarrow 0$.

If we describe every route trip between public transport stops $q$ and $w$ using the proposed two-dimensional coordinates system, the Equation (3) will transformed to:

$$
\sum_{q=1}^{b} l_{H q}=\sum_{q=1}^{b} \sqrt{\left(x_{H}-x_{q}\right)^{2}+\left(y_{H}-y_{q}\right)^{2}}=F,
$$

where: $b$ is the total number of trips that are serviced by the hub; $F$ is the function reflecting the general deviation of the hub location and start/stop points of trips after the transfer $[\mathrm{km}]$.

The optimal value of the $F$ function can be obtained by application of the partial derivation method. Therefore, we have the following:

$$
\begin{gathered}
\frac{\partial F}{\partial x_{H}}=\sum_{q=1}^{b} \frac{2 \cdot x_{H}-2 \cdot x_{q}}{2 \cdot \sqrt{\left(x_{H}-x_{q}\right)^{2}+\left(y_{H}-y_{q}\right)^{2}}} ; \\
\frac{\partial F}{\partial y_{H}}=\sum_{q=1}^{b} \frac{2 \cdot y_{H}-2 \cdot y_{q}}{2 \cdot \sqrt{\left(x_{H}-x_{q}\right)^{2}+\left(y_{H}-y_{q}\right)^{2}}} .
\end{gathered}
$$

After the appropriate transformation the optimum of $F$ will be obtained after solving the following set of homogeneous equations:

$$
\left\{\begin{array}{l}
\sum_{q=1}^{b} \frac{x_{H}-x_{q}}{\sqrt{\left(x_{H}-x_{q}\right)^{2}+\left(y_{H}-y_{q}\right)^{2}}}=0 \\
\sum_{q=1}^{b} \frac{y_{H}-y_{q}}{\sqrt{\left(x_{H}-x_{q}\right)^{2}+\left(y_{H}-y_{q}\right)^{2}}}=0 .
\end{array}\right.
$$

Having solved Equation (10) we can determine the values of parameters $x_{H}$ and $y_{H}$ giving the information about optimal location of the transport hub.

The next component of the passenger trip time is waiting time at the public transport stop. The variety of the models to value estimation exists. However, all of them can be divided into two branches: the first one is based on a hypothesis about the deterministic nature of this process and the second one supposes this process as stochastic. Each of these approaches may be implemented for waiting time modelling. However, some deviations in their movements may occur, even though the route vehicle adheres strongly to the time schedule. For this reason, it has been proposed to estimate the waiting time on the base of the following formula (Naumov 2019):

$$
d_{s}=\frac{I_{m}}{2}+\xi,
$$

where: $d_{s}$ is waiting time at the public transport stop [min]; $\xi$ is the stochastic component reflecting possible time schedule deviation [min].

The density of the public transport stops $\rho_{s}$ influences on transport accessibility through time indices, which reflect two types of time formation: transportation process execution on the route (Comi et al. 2017) and vehicles dwell time at the public transport stops (Huo et al. 2018):

$$
d_{d}=d_{v}+d_{l}+d_{p},
$$

where: $d_{d}$ is the part of the travel time that is a function of the number of stops on the public transport route [min]; $d_{v}$ is the direct trip time in the route vehicle [min]; $d_{l}$ is the passenger walk time to reach the nearest public transport stop [min]; $d_{p}$ is the total dwell time of the route vehicle in the case of one trip, depending on quantity of public transport stops on the route [min]. 
The travel time realization $d_{v}$ and the total dwell time of the route vehicle $d_{p}$ are calculated by widely-known and well-formalized formulas. As for passenger walk time to reach the nearest public transport stop $d_{l}$ it has been proposed to define this value according the following (Figure 1):

$$
d_{l}=\frac{1}{V_{p}} \cdot \sqrt{\left(\frac{l_{r}}{2 \cdot n}\right)^{2}+l_{k}^{2}} .
$$

The general form of the Equation (12) shows functional interdependence, so the decomposition has been made. As a result, the following formula has been obtained:

$$
d_{d}=\frac{l_{t}}{V_{t}}+\frac{1}{V_{p}} \cdot \sqrt{\left(\frac{l_{r}}{2 \cdot n}\right)^{2}+l_{k}^{2}}+k \cdot n \cdot \frac{l_{t}}{l_{r}},
$$

where: $l_{t}$ is the travel distance executed on a given route of city public transport $[\mathrm{km}] ; V_{t}$ is road speed of route vehicle $[\mathrm{km} / \mathrm{h}] ; l_{r}$ is the length of passenger route (line) $[\mathrm{km}]$; $n$ is the number of public transport stops on the route (line) [unit]; $l_{k}$ is the shortest walking distance from place of residence to the nearest public transport stop $[\mathrm{km}] ; V_{p}$ is the average speed by walk $[\mathrm{km} / \mathrm{h}] ; k$ is the average dwell time of route vehicle at one public transport stop [h].

As we can see, the Equation (14) has the quadratic dependences and the radicand. These mathematical functionalities are substantiated by the following processes. Every passenger takes a walk to reach the nearest public transport stop when meeting their own demand for travels using some modes of public transit. The walk distance depends on density of public transport stops on the city routes and their spatial distribution. It is obviously that the passenger aspires to minimize the general travel time by reducing time expenditures on every basic process such as walk time, waiting time, transfer time, etc. In that context, the pedestrian accessibility significantly influences on the general assessment of public network functioning (Yang et al. 2013) and acts as the basis for passengers' choice of modes. The walk time depending on walk distance can be minimized by definition of the shortest path to the public transport stop (Zhang et al. 2012). The ideal walk path would be made by the shortest distance, which is the perpendicular from the place of residence to bus stop. This can be true under assuming the Euclidean metric implementation, unlike the "taxicab geometry". We have to notice that most of the large European cities have a radial ring structure to the road network, that is why the assumption about the Euclidean metric is valid.

Such an idealistic approach to shortest path determination could lead to the necessity of arranging the number of public transport stops equal to the number of the O-D pairs. In this case, it will result in a significant increase of route vehicle dwell time on all stops within one trip, which contradict the paradigm of passenger transport service. Therefore, according to the above-mentioned, the walk distance from the place of residence to the nearest public transport stop can be defined (simulated) as Euclidean distance (Figure 1).

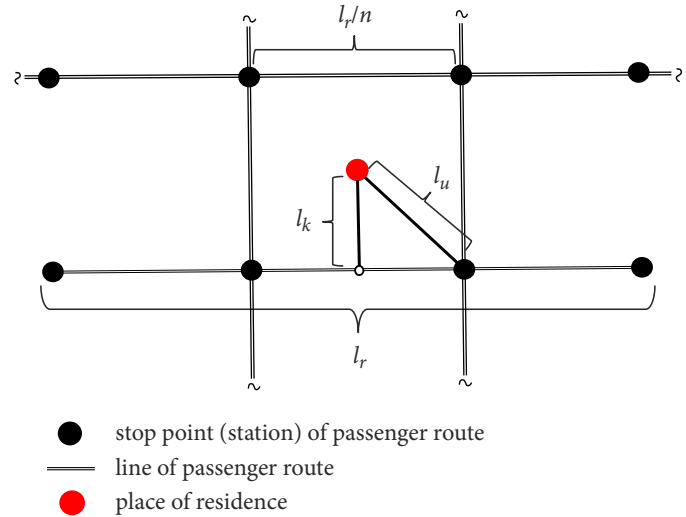

Figure 1. The scheme definition of walk distance from the place of residence to the nearest stop

To obtain the optimum quantity of public transport stops on the route it has been used the differentiation procedure in the case of Equation (14). The partial derivative has been executed on parameter $n$ :

$$
\frac{\partial d_{d}}{\partial n}=\frac{l_{t} \cdot k}{l_{r}}-\frac{l_{r}^{2}}{4 \cdot n^{3} \cdot V_{p} \cdot \sqrt{l_{k}^{2}+\left(\frac{l_{r}}{n \cdot 2}\right)^{2}}} .
$$

The first step assumes obtaining the linear form of the Equation (15). As the result, we have:

$$
4 \cdot l_{t} \cdot k \cdot n^{3} \cdot V_{p} \cdot \sqrt{l_{k}^{2}+\frac{l_{r}^{2}}{4 \cdot n^{2}}}=l_{r}^{3} .
$$

The left side of the Equation (16) contains the parameter $n$ to be defined. The mathematical transformations require to eliminate the square root at the left side of the Equation (16). To do this we have taken the square of the left and the right sides of the Equation (16). As the result, we had the following:

$$
16 \cdot l_{t}^{2} \cdot k^{2} \cdot n^{6} \cdot V_{p}^{2} \cdot\left(l_{k}^{2}+\frac{l_{r}^{2}}{4 \cdot n^{2}}\right)=l_{r}^{6} .
$$

The next step requires to open the brackets (Equation (18)) and to leave only the desired parameter $n$ from the left side of the Equation (19):

$$
\begin{aligned}
& 16 \cdot l_{t}^{2} \cdot k^{2} \cdot n^{6} \cdot V_{p}^{2} \cdot l_{k}^{2}+4 \cdot l_{t}^{2} \cdot k^{2} \cdot n^{4} \cdot V_{p}^{2} \cdot l_{r}^{2}=l_{r}^{6} ; \\
& 4 \cdot l_{t}^{2} \cdot k^{2} \cdot V_{p}^{2} \cdot\left(4 \cdot n^{6} \cdot l_{k}^{2}+n^{4} \cdot l_{r}^{2}\right)= \\
& l_{r}^{6} \Rightarrow 4 \cdot n^{6} \cdot l_{k}^{2}+n^{4} \cdot l_{r}^{2}=\frac{l_{r}^{6}}{4 \cdot l_{t}^{2} \cdot k^{2} \cdot V_{p}^{2}} .
\end{aligned}
$$

To achieve the standard view of the equation it has been executed the change of variable. For this reason, the $n^{2}$ will be signified as $z$. Making the substitution of $n^{2}$ as $z$ in Equation (19) we have obtained the following cubic equation as the result:

$$
4 \cdot z^{3} \cdot l_{k}^{2}+z^{2} \cdot l_{r}^{2}=\frac{l_{r}^{6}}{4 \cdot l_{t}^{2} \cdot k^{2} \cdot V_{p}^{2}} .
$$

The next step is to make the transformation of Equation (20) to get the coefficient of $z^{3}$ that is equal to 1 . 
This condition is fulfilled via division of Equation (20) on component $4 \cdot l_{k}^{2}$. As the result the following has been obtained:

$$
z^{3}+\frac{l_{r}^{2}}{4 \cdot l_{k}^{2}} \cdot z^{2}=\frac{l_{r}^{6}}{16 \cdot l_{t}^{2} \cdot l_{k}^{2} \cdot k^{2} \cdot V_{p}^{2}} .
$$

The obtained form of Equation (21) has the cubic degree, which assumes the existence of only one positive root. The Equation (21) under condition $z=n^{2}$ allows to define the optimal value of public transport stops number for every passenger route. As the method to define the parameter $z$ from Equation (21) the numerical technique may be applied. The obtained equation is of nonlinear type and may be solved by gradient descent or Newton method. As the tool for the $z$ parameter definition we propose to applicate the Solver Add-In in Microsoft Excel.

The value of parameter $l_{t}$ has to be obtained experimentally on the base of the survey or simulated proceeding from the O-D matrix. In turn, the ideal shortest way to the nearest public transport stop $l_{k}$ may be evaluated by Zilbertal's model:

$$
l_{k}=\frac{1}{3 \cdot \rho_{r}},
$$

where: $\rho_{r}$ is density of transport network $[1 / \mathrm{km}]$.

The developed theoretical basis of this passenger transport accessibility assessment considers the character of the transportation service and will allow to form the list of engineering and administrative measures in terms of longrange and current planning with high effectiveness and precision.

\section{Simulation transport hub influence on city public transport accessibility}

The estimation of transport accessibility has been proposed to implement via the PTV VISUM making the simulation the public transport functioning. The experimental research supposes the assessment of two states of public transport network: the current situation and the "after optimization procedure" state. Both of them have to be based on statistical information about the spatial parameters of the transport system, time characteristics of the demand for travels and operating schedules of route vehicles. For the purposes of this research, one of the most labour-intensive Kharkiv City (Ukraine) administrative units - the Industrial District - has been chosen. Its general characteristics are presented in Figure 2.

The chosen city district has a significant attraction of industrial labour activities, as illustrated in Figure 2. However, the other business layers are rather developed in this area too. This district includes 1 big and 6 small markets, 20 supermarkets, 400 grocery stores, 67 public catering enterprises and 147 consumer services companies. The specific content in the table in Figure 2 reflects the level of the specific weight for Industrial District in the city territory.

As has been seen the Industrial District made up 11\% of Kharkiv City population and $10 \%$ of the city area. The major parameter of the study object is the specific weight in large enterprise number. Industrial District contains more than half (53\%) of Kharkiv City large enterprises number making the high labour attraction in frame of the city area. The number of small business enterprises is not so big, but the general amount of the Industrial District employees is of significant range in the case of entire city. The location of all these infrastructure objects influences on the character of trips fulfilled by public transport. The transport network of the Industrial District is well-developed, described in more detail in Table 1.

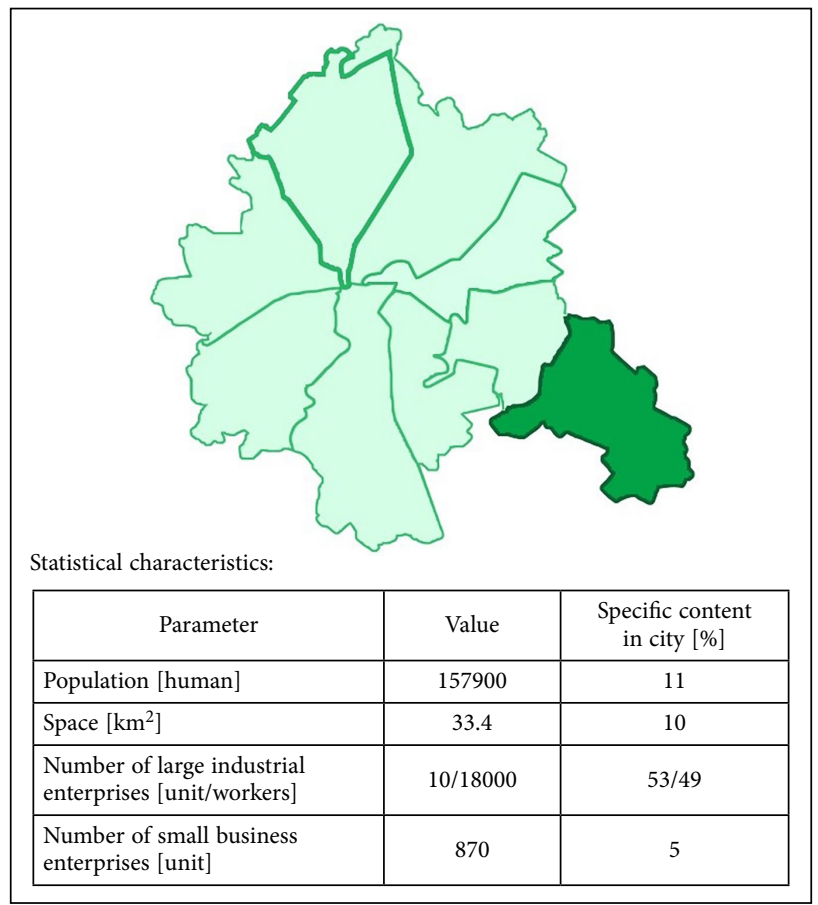

Figure 2. Scheme and statistical characteristics of the Industrial District of Kharkiv City

Table 1. The spatial and quantitative characteristics of the public transport network in the Industrial District (source: research by authors)

\begin{tabular}{|l|l|c|}
\hline \multicolumn{2}{|c|}{ Parameter } & Numeric value \\
\hline \multirow{4}{*}{$\begin{array}{l}\text { Number of routes } \\
\text { (lines) [units] }\end{array}$} & subway & 1 \\
\cline { 2 - 3 } & trolleybus & 5 \\
\cline { 2 - 3 } & bus & 19 \\
\cline { 2 - 3 } & tram & 2 \\
\hline \multirow{4}{*}{$\begin{array}{l}\text { The route network } \\
\text { length [km] }\end{array}$} & subway & 3 \\
\cline { 2 - 3 } & trolleybus & 17.07 \\
\cline { 2 - 3 } & bus & 113.02 \\
\cline { 2 - 3 } & tram & 9.28 \\
\cline { 2 - 3 } & general & 142.37 \\
\hline The transport network length [km ] & 50.81 \\
\hline The residential area space $\left[\mathrm{km}^{2}\right]$ & 20.04 \\
\hline Routes length to road network length ratio & 2.7 \\
\hline \multicolumn{2}{|l}{ Routing network density $\left[\mathrm{km}^{2} / \mathrm{km}^{2}\right]$} & 2.54 \\
\hline
\end{tabular}


The current state of the public transport network was simulated in the PTV VISUM environment. The model obtained consists of 177 nodes, 210 lines with a total length of $52.86 \mathrm{~km}, 4$ modes of transportation, 116 public transport stops, 3 subway stations and 30 transport zones. Figure 3 shows the route network scheme with differentiation of public transport modes.

The obtained model allows to execute the estimation of transport accessibility via simulation of total travel time in the chosen city district. First of all, the travels distribution within the Industrial area has to be found. From a transport engineering point of view, the most acceptable and correct way is to form the O-D matrix. Increased simulation accuracy is obtained by exact calculation of the O-D matrix, which is a rather difficult scientific problem. The results with the highest accuracy are obtained by undertaking a questionnaire survey resulting in huge labour intensity and financial expense (Kulpa, Szarata 2016). In this case, if there is a lack of labour or financial deficit this procedure can be replaced by modelling based on some physical or statistical hypotheses. The negative side of this process is possible deviation of the calculated results from the distribution of real trips. Widely-used gravity-based models can lead to high deviation of the obtained results from real ones and give zero intra zone O-D travels. Taking these features into account the O-D matrix calculation has been made using the equal probability approach (Rossolov 2016). The first step of the O-D matrix determination assumes the definition of transport zone capacities on origin and destination. It is obviously that the density of population, density of labour sites in each transport zone and area of each zone are of the biggest influence on these two values. The second step supposes the implementation of trip modelling according to the chosen hypothesis of trip distribution by city territory. To obtain the demand for passenger transport service according to the two above-mentioned steps the transport zones in the chosen city's district have been formed. This procedure has been executed according to following: the structure of transport zone must be homogeneous, its borders must not divide buildings, industrial and recreational areas. The transport zones boarders have been set on the streets of the Industrial District. The zone sizes have to be characterized by small variance. The resulting transport zones made in PTV VISUM software are shown in Figure 4.

The obtained values of transport zones space are the base for calculation of the origin and destination volumes. The density of inhabitants in the transport zones has been estimated from building type (number of floors) and their locations. In turn, the labour density of the transport zones has been evaluated according to enterprise quantity and their capacity. The obtained parameters have been used for computation of transport zone capacities (origin and destination) and the O-D matrix simulation. The quantitative characteristics of the transport zones (origin and destination) and O-D matrix for the Industrial District are presented in Table 2 .

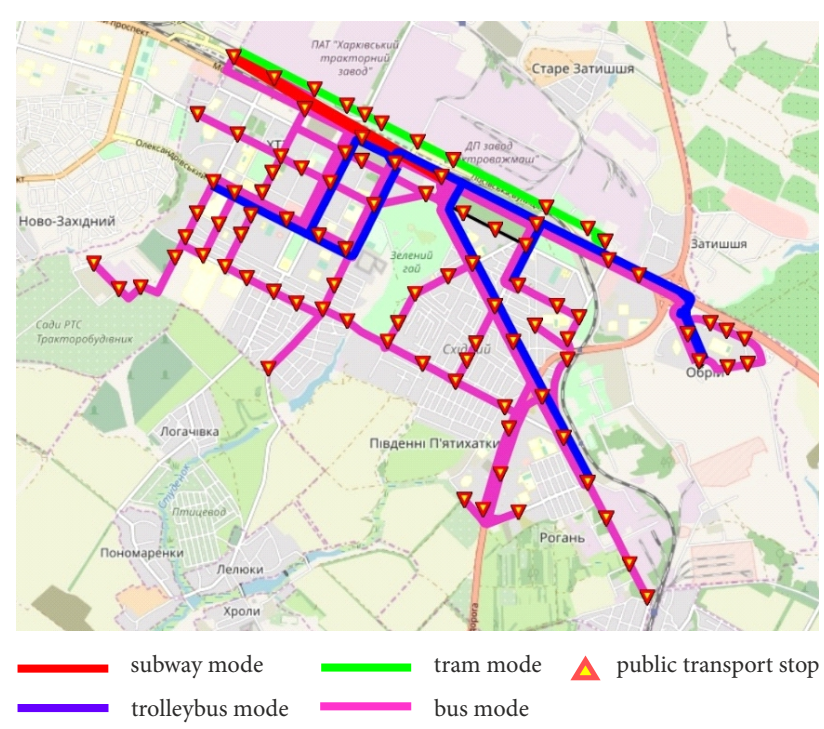

Figure 3. The current public transport network of the Industrial District

\begin{tabular}{|c|c|c|c|c|c|}
\hline & \\
\hline
\end{tabular}

Figure 4. Results of transport zones formation 
As the travel time simulation is supposed to be done for the morning peak-hours (6 a.m. - 10 a.m.), the O-D matrix has been constructed for the same period and presented in the Appendix.

Within this study, the estimation of transport network accessibility has been proposed to fulfil through determi-

Table 2. The demand for public transport service characteristics (source: research by authors)

\begin{tabular}{|l|l|c|}
\hline \multicolumn{1}{c|}{$\begin{array}{c}\text { Demand } \\
\text { element }\end{array}$} & \multicolumn{1}{c|}{$\begin{array}{c}\text { Statistical } \\
\text { characteristics }\end{array}$} & $\begin{array}{c}\text { Numeric } \\
\text { values }\end{array}$ \\
\hline \multirow{4}{*}{ Origin [pass] } & Minimum & 170 \\
\cline { 2 - 3 } & Maximum & 6085 \\
\cline { 2 - 3 } & Mean & 1667 \\
\cline { 2 - 3 } & Standard deviation & 1155.8 \\
\cline { 2 - 3 } & Total number & 50000 \\
\hline \multirow{5}{*}{ Destination [pass] } & Minimum & 292 \\
\cline { 2 - 3 } & Maximum & 8721 \\
\cline { 2 - 3 } & Mean & 1667 \\
\cline { 2 - 3 } & Standard deviation & 2101.6 \\
\cline { 2 - 3 } & Total number & 50000 \\
\hline \multirow{5}{*}{ O-D travels [pass] } & Minimum & 1 \\
\cline { 2 - 3 } & Maximum & 1061 \\
\cline { 2 - 3 } & Mean & 56 \\
\cline { 2 - 3 } & Standard deviation & 93.5 \\
\cline { 2 - 3 } & Total number & 50000 \\
\hline
\end{tabular}

a)

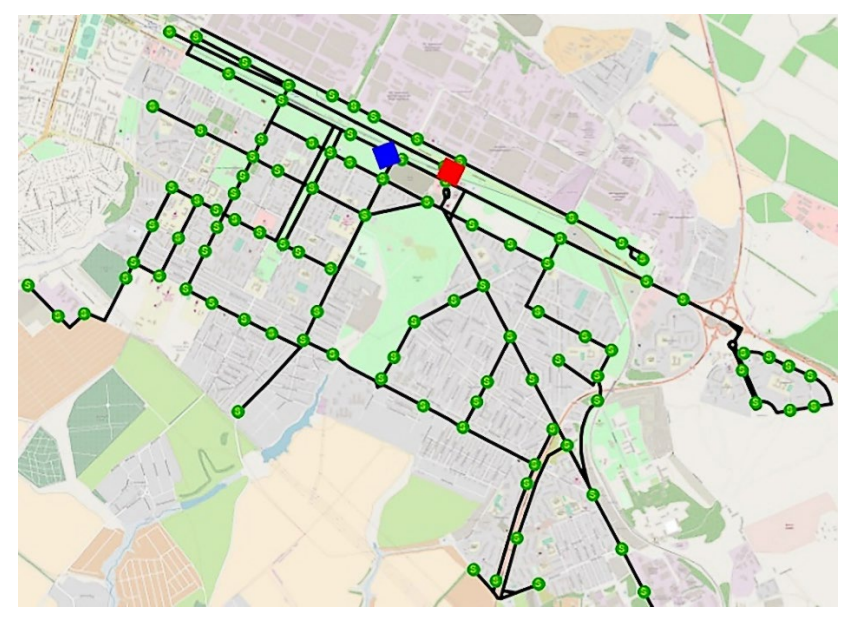

nation of the rational transport hub location. The major problem of the Kharkiv City's Industrial District considered in work is coordination of transfer passenger flows at the station "Industrialna" to the final station of trolleybus routes " 12 Aprelia". Their current location is shown in Figure $5 \mathrm{a}$ and the proposed variant in Figure $5 \mathrm{~b}$.

In Figure 5 the location of the subway hub is marked by a red square and the trolleybus hub by the blue square. The current distance between two hubs is $0.623 \mathrm{~km}$, which, according to the survey, the passengers need to cover by walk. This allows passengers to reduce their trip costs but increases the total travel time. Therefore, it has been proposed to change the location of the trolleybus hub to reduce the walking distance to $0.142 \mathrm{~km}$ or by $77.2 \%$ when compared with the current state.

To estimate the transport accessibility of the public transport network in the Industrial District, the travel time for both variants of trolleybus hub location has been simulated. The simulation procedure has been made using the PTV VISUM software. The results are shown in Table 3 .

The total time expenditures reduction in percentages (last column in Table 3 ) shows the results of qualitative estimation in the case of the hub relocation. It has been estimated as follows:

$$
\Delta T E(\%)=\frac{T E^{\text {current }}-T E^{\text {rational }}}{T E^{\text {current }}} \cdot 100,
$$

where: $\Delta T E(\%)$ is the reduction volume of total time ex-

b)

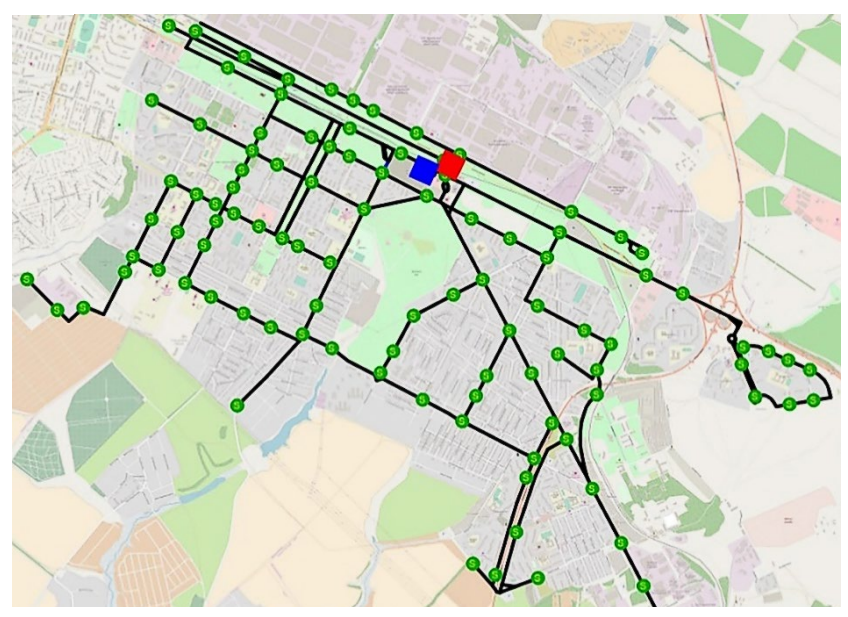

Figure 5. Current (a) and proposed (b) locations of transport hub in the Kharkiv City's Industrial District

Table 3. Results of trip time simulation (source: research by authors)

\begin{tabular}{|l|c|c|c|c|}
\hline \multirow{2}{*}{ Parameter } & \multicolumn{2}{|c|}{ Hub location } & \multicolumn{2}{c|}{ Reduction volume } \\
\cline { 2 - 5 } & $\begin{array}{c}\text { current } \\
(0.623 \mathrm{~km})\end{array}$ & $\begin{array}{c}\text { rational } \\
(0.142 \mathrm{~km})\end{array}$ & minutes per one peak-hours period & percentage \\
\hline $\begin{array}{l}\text { General time expenditures for trip } \\
\text { realization in one peak-hours period } \\
T E \text { [min-pass] }\end{array}$ & 1257749.6 & 1183475.7 & 74273.9 & 5.9 \\
\hline Average trip time [min] & 25.15 & 23.67 & 1.48 & \multirow{2}{*}{} \\
\hline
\end{tabular}


penditures [\%]; $T E^{\text {current }}$ is the total time expenditures for travels realization in one peak-hours period under current hub location [min]; $T E^{\text {rational }}$ is the total time expenditures for travels realization in one peak-hours period under rational hub location [min].

As it is shown in Table 3 the total time expenditures reduction in percentage is the similar to travel time decrease. This can be explained by constant of the travel total number for both scenarios: current hub location and rational one. The statistical significance of the obtained result has been checked by $t$-test to determine the probability of difference between two samples. The tabular value of the critical $t$-criterion under probability 0.05 equals to 1.96 with degree of freedom 898 . The calculated value of the $t$-criterion is bigger than critical one and equals 2.59. According to this, the conclusion about the statistical significance of differences in the average travel time has been made.

As has been seen, the proposed location of the trolleybus hub allows to reduce the travel time up to approximately $6 \%$. This in turn leads to an annual saving of passenger's time in an amount of $598483 \mathrm{~h}$ taking into account the two peak-hours periods per a day, the number of workdays and the general volume of the passengers serviced in the Industrial District. The obtained time saving can be extrapolated to a monetary equivalent on the basis of average monthly salary, quantity of workdays per

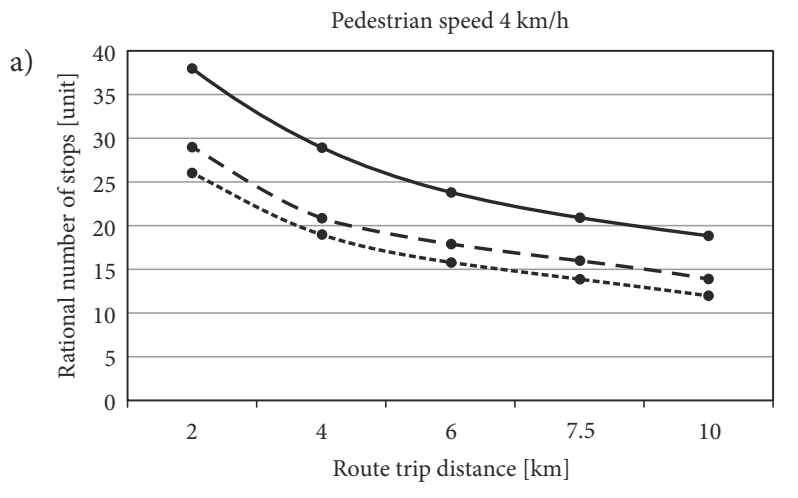

$\longrightarrow$ vehicle dwell time at the stop $10 \mathrm{~s} \quad-\bullet-$ vehicle dwell time at the stop $20 \mathrm{~s}$ b)

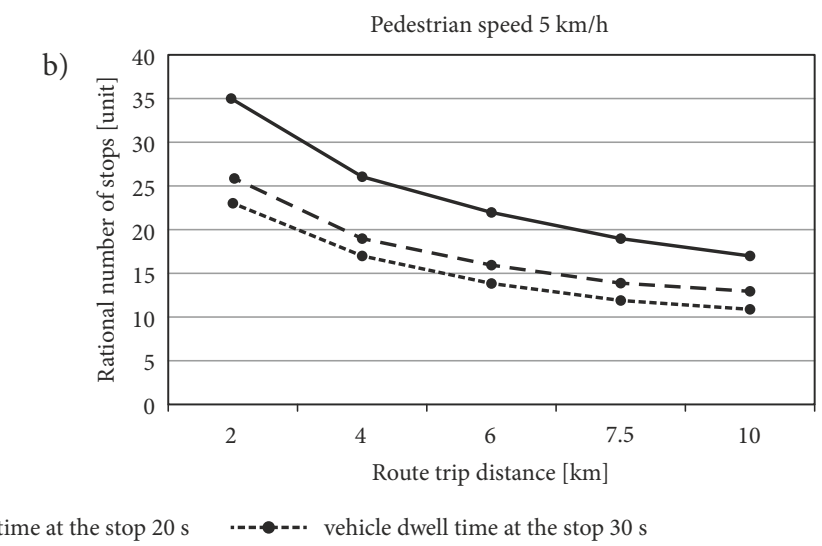

Figure 6. Regularities of rational number of public transport stops variance for the public transit
Pedestrian speed $4 \mathrm{~km} / \mathrm{h}$

a)

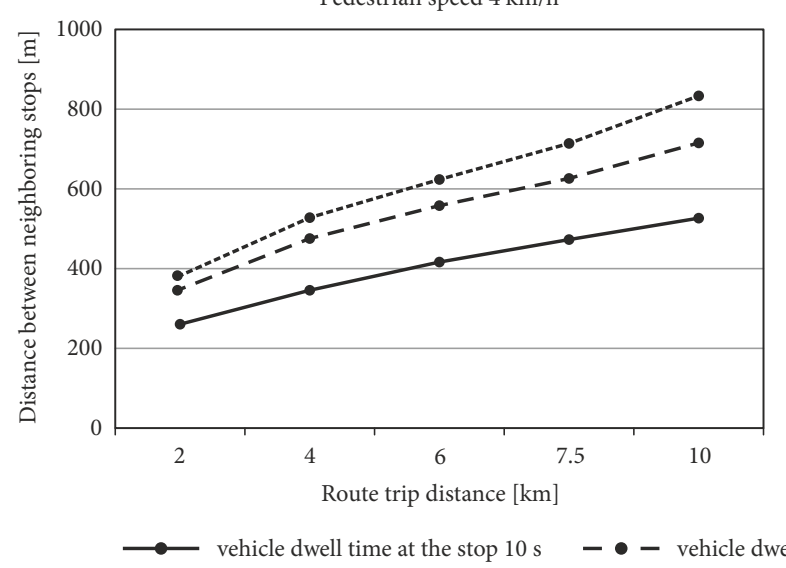

month and average duration of a workday. According to statistics from the pension capital fund of Ukraine, the current average monthly salary is $6598 \mathrm{UAH}$. Considering the number of working days as 22 with a working time duration of $8 \mathrm{~h}$, the amount of annual economic effect would come to $22443125 \mathrm{UAH}$.

The proposed rational hub location has been defined according to the models developed - Equations (7) and (10). This approach is a similar one to the Center of Gravity Method. Rational hub location has to provide a minimization of pedestrian turnover and increase the on-foot and transport accessibility of public transport. According to the simulations done, this parameter is of the following numerical values: current hub location - 576.9 pass$\mathrm{km}$ in one peak-hour period, proposed hub location 131.5 pass-km in one peak-hour period.

Transport accessibility also has been studied in case of rational number of stops (stations) on the city passenger route. Using model (Equation (21)) under condition $z=n^{2}$ the following regularities have been obtained (Figure 6). The modelling of rational public transport stops number on the city transit route has been made under following conditions: route length $-10 \mathrm{~km}$, average pedestrian walk speed in Figure $6 \mathrm{a}-4 \mathrm{~km} / \mathrm{h}$, in Figure $6 \mathrm{~b}-5 \mathrm{~km} / \mathrm{h}$ ) and the shortest way to the nearest stop point $l_{k}$ was equalled to $0.13 \mathrm{~km}$, obtained by (Equation (14)) and data from Table 1 . 
Based on the data in Figure 6 the average distance between neighbouring stop points has been calculated. This has been executed for the same basic route of $10 \mathrm{~km}$ length. The obtained regularities are presented in Figure 7.

As has been seen, the rational distance between neighbouring stop points on the city bus route changes significantly because of variance of vehicle dwell time, average speed of pedestrians and distance that the passenger covers during the trip in the route vehicle. Based on these results we can draw the conclusion that transport accessibility improvement has to be fulfilled not only through technical measures but imperatively with technological optimization too. This will allow to reduce the undesirable losses of passenger's time and guarantee the minimum efforts for travels to be made.

\section{Conclusions}

The proposed models of transport accessibility estimation allow to reduce the transfer and total travel time for the HLP improvement. It has been proposed to use the combined criterion for the HLP solving based on two-dimensional coordinate system with estimation of passengers walk turnover in the hub area. The widely-used transportation cost criterion in the case of HLP has been changed on passenger turnover because the walk transfer distance between modes had the big influence of hub location under the made research. The problem of passengers' transfer between rapid transit (subway) station and trolleybus lines has been solved by definition of trolleybus terminal stop location to reduce the passengers walk turnover. The rational transport hub location has been determined by the derivation procedure implementation. As the subject of the research, the Industrial District of Kharkiv City has been used which forms more than $50 \%$ of city employment places in the case of large industrial enterprises. The pedestrian turnover simulation under current and optimal hub location has been made for the Industrial District. As a consequence of optimization, the total pedestrian turnover for one peak-hours period has been reduced from 576.9 pass-km (current hub location) to 131.5 pass$\mathrm{km}$ (determined optimal hub location). The total annual economic effect due to the rational hub location has been estimated as 22 million UAH (801 thousand EUR). Under the study the O-D matrix has been simulated only for the Industrial District. However, the actual number of the arrived passengers from other city's areas will form the bigger economic effect than it has been forecasted for the local travels in the case of the Industrial District.

The second branch of the study has been dealt with transport accessibility evaluation under the public transport stop number variation. The model of optimal stops number has been determined by derivation procedure of the travel time function. It has been estimated the change in rational stops number under variation of the average trip distance, passengers walk speed and vehicle dwell time. The rational stops number will be increased if the average trip distance of the passengers decreases. Besides that, it has been determined that the increase of public transport accessibility may be achieved by the reduction of the vehicles dwell time at the stops. Regarding to the children or senior citizens that characterized by lower walk speed comparing with adult one the rational number of public transport stops must be formed on the simulation results for $4 \mathrm{~km} / \mathrm{h}$ pedestrian speed. The analogic regularities have been determined for the rational distance values between the neighbouring stops.

\section{Author contributions}

Alexander Rossolov - conceptualization, methodology, formal analysis, investigation, data curation, writing (original draft), writing (review and editing), supervision.

Vitalii Naumov - methodology, formal analysis, investigation, writing (review and editing), supervision.

Nadezhda Popova - data curation, writing (review and editing).

Ekaterina Vakulenko - visualization, resources.

Olena Levchenko - visualization, resources. 


\section{Appendix}

The O-D matrix for peak-hours period (6 a.m. - 10 a.m.) for Kharkiv City Industrial District

\begin{tabular}{|c|c|c|c|c|c|c|c|c|c|c|c|c|c|c|c|c|c|c|c|c|c|c|c|c|c|c|c|c|c|c|c|}
\hline & \multicolumn{31}{|c|}{ Destination } \\
\hline \multirow{31}{*}{ 咅 } & $\begin{array}{l}\text { Transport } \\
\text { zone No }\end{array}$ & 1 & 2 & 3 & 4 & 5 & 6 & 7 & 8 & 9 & 10 & 11 & 12 & 13 & 14 & 15 & 16 & 17 & 18 & 19 & 20 & 21 & 22 & 23 & 24 & 25 & 26 & 27 & 28 & 29 & 30 \\
\hline & 1 & 38 & 159 & 312 & 35 & 143 & 139 & 208 & 80 & 18 & 21 & 43 & 42 & 18 & 35 & 60 & 38 & 21 & 53 & 66 & 32 & 58 & 31 & 17 & 446 & 146 & 24 & 20 & 27 & 502 & 44 \\
\hline & 2 & 6 & 24 & 47 & 5 & 21 & 21 & 31 & 12 & 3 & 3 & 7 & 6 & 3 & 5 & 9 & 6 & 3 & 8 & 10 & 5 & 9 & 5 & 3 & 67 & 22 & 4 & 3 & 4 & 75 & 7 \\
\hline & 3 & 13 & 55 & 107 & 12 & 49 & 48 & 71 & 27 & 6 & 7 & 15 & 14 & 6 & 12 & 21 & 13 & 7 & 18 & 23 & 11 & 20 & 11 & 6 & 153 & 50 & 8 & 7 & 9 & 172 & 15 \\
\hline & 4 & 13 & 55 & 108 & 12 & 50 & 48 & 72 & 28 & 6 & 7 & 15 & 14 & 6 & 12 & 21 & 13 & 7 & 18 & 23 & 11 & 20 & 11 & 6 & 155 & 51 & 8 & 7 & 9 & 174 & 15 \\
\hline & 5 & 2 & 9 & 18 & 2 & 8 & 8 & 12 & 5 & 1 & 1 & 3 & 2 & 1 & 2 & 4 & 2 & 1 & 3 & 4 & 2 & 3 & 2 & 1 & 26 & 9 & 1 & 1 & 2 & 30 & 3 \\
\hline & 6 & 9 & 36 & 71 & 8 & 33 & 32 & 48 & 18 & 4 & 5 & 10 & 10 & 4 & 8 & 14 & 9 & 5 & 12 & 15 & 7 & 13 & 7 & 4 & 102 & 33 & 6 & 5 & 6 & 115 & 10 \\
\hline & 7 & 22 & 91 & 178 & 20 & 82 & 79 & 119 & 46 & 11 & 12 & 25 & 24 & 10 & 20 & 34 & 22 & 12 & 30 & 38 & 19 & 33 & 18 & 10 & 255 & 84 & 14 & 11 & 15 & 287 & 25 \\
\hline & 8 & 80 & 337 & 659 & 74 & 302 & 293 & 440 & 169 & 39 & 45 & 92 & 88 & 38 & 73 & 127 & 81 & 43 & 112 & 140 & 69 & 124 & 65 & 36 & 943 & 309 & 51 & 42 & 57 & 1061 & 94 \\
\hline & 9 & 14 & 58 & 114 & 13 & 52 & 50 & 76 & 29 & 7 & 8 & 16 & 15 & 6 & 13 & 22 & 14 & 7 & 19 & 24 & 12 & 21 & 11 & 6 & 162 & 53 & 9 & 7 & 10 & \begin{tabular}{|l|}
183 \\
\end{tabular} & 16 \\
\hline & 10 & 16 & 67 & 130 & 15 & 60 & 58 & 87 & 33 & 8 & 9 & 18 & 17 & 7 & 14 & 25 & 16 & 9 & 22 & 28 & 14 & 24 & 13 & 7 & 187 & 61 & 10 & 8 & 11 & 210 & 19 \\
\hline & 11 & 5 & 23 & 45 & 5 & 20 & 20 & 30 & 11 & 3 & 3 & 6 & 6 & 3 & 5 & 9 & 5 & 3 & 8 & 9 & 5 & 8 & 4 & 2 & 64 & 21 & 3 & 3 & 4 & 72 & 6 \\
\hline & 12 & 47 & 197 & 386 & 44 & 177 & 172 & 257 & 99 & 23 & 26 & 54 & 52 & 22 & 43 & 74 & 48 & 25 & 66 & 82 & 40 & 72 & 38 & 21 & 552 & 181 & 30 & 25 & 33 & 621 & 55 \\
\hline & 13 & 13 & 56 & 110 & 12 & 51 & 49 & 74 & 28 & 7 & 7 & 15 & 15 & 6 & 12 & 21 & 14 & 7 & 19 & 23 & 11 & 21 & 11 & 6 & 158 & 52 & 9 & 7 & 10 & 178 & 16 \\
\hline & 14 & 22 & 91 & 178 & 20 & 82 & 79 & 119 & 46 & 11 & 12 & 25 & 24 & 10 & 20 & 34 & 22 & 12 & 30 & 38 & 19 & 33 & 18 & 10 & 255 & 84 & 14 & 11 & 15 & 287 & 25 \\
\hline & 15 & 15 & 63 & 124 & 14 & 57 & 55 & 82 & 32 & 7 & 8 & 17 & 17 & 7 & 14 & 24 & 15 & 8 & 21 & 26 & 13 & 23 & 12 & 7 & 177 & 58 & 10 & 8 & 11 & 199 & 18 \\
\hline & 16 & 24 & 101 & 198 & 22 & 91 & 88 & 132 & 51 & 12 & 13 & 27 & 26 & 11 & 22 & 38 & 24 & 13 & 34 & 42 & 21 & 37 & 20 & 11 & 283 & 93 & 15 & 13 & 17 & 318 & 28 \\
\hline & 17 & 15 & 65 & 127 & 14 & 58 & 56 & 85 & 33 & 8 & 9 & 18 & 17 & 7 & 14 & 24 & 16 & 8 & 22 & 27 & 13 & 24 & 13 & 7 & 182 & 60 & 10 & 8 & 11 & 204 & 18 \\
\hline & 18 & 27 & 112 & 218 & 25 & 100 & 97 & 146 & 56 & 13 & 15 & 30 & 29 & 12 & 24 & 42 & 27 & 14 & 37 & 46 & 23 & 41 & 22 & 12 & 312 & 102 & 17 & 14 & 19 & 351 & 31 \\
\hline & 19 & 33 & 139 & 272 & 31 & 125 & 121 & 181 & 70 & 16 & 18 & 38 & 36 & 16 & 30 & 52 & 34 & 18 & 46 & 58 & 28 & 51 & 27 & 15 & 389 & 127 & 21 & 17 & 24 & 437 & 39 \\
\hline & 20 & 20 & 85 & 167 & 19 & 77 & 74 & 111 & 43 & 10 & 11 & 23 & 22 & 10 & 19 & 32 & 21 & 11 & 28 & 35 & 17 & 31 & 17 & 9 & 239 & 78 & 13 & 11 & 14 & 269 & 24 \\
\hline & 21 & 29 & 123 & 241 & 27 & 110 & 107 & 160 & 62 & 14 & 16 & 33 & 32 & 14 & 27 & 46 & 30 & 16 & 41 & 51 & 25 & 45 & 24 & 13 & 344 & 113 & 19 & 15 & 21 & 387 & 34 \\
\hline & 22 & 15 & 65 & 127 & 14 & 58 & 56 & 85 & 33 & 8 & 9 & 18 & 17 & 7 & 14 & 24 & 16 & 8 & 22 & 27 & 13 & 24 & 13 & 7 & 182 & 60 & 10 & 8 & 11 & 204 & 18 \\
\hline & 23 & 15 & 62 & 121 & 14 & 55 & 54 & 81 & 31 & 7 & 8 & 17 & 16 & 7 & 13 & 23 & 15 & 8 & 21 & 26 & 13 & 23 & 12 & 7 & 173 & 57 & 9 & 8 & 10 & 194 & 17 \\
\hline & 24 & 21 & 88 & 172 & 19 & 79 & 76 & 115 & 44 & 10 & 12 & 24 & 23 & 10 & 19 & 33 & 21 & 11 & 29 & 36 & 18 & 32 & 17 & 9 & 246 & 81 & 13 & 11 & 15 & 277 & 24 \\
\hline & 25 & 21 & 90 & 175 & 20 & 80 & 78 & 117 & 45 & 10 & 12 & 24 & 23 & 10 & 19 & 34 & 22 & 12 & 30 & 37 & 18 & 33 & 17 & 9 & 251 & 82 & 14 & 11 & 15 & 282 & 25 \\
\hline & 26 & 15 & 64 & 125 & 14 & 57 & 56 & 84 & 32 & 7 & 8 & 17 & 17 & 7 & 14 & 24 & 15 & 8 & 21 & 27 & 13 & 23 & 12 & 7 & 179 & 59 & 10 & 8 & 11 & 202 & 18 \\
\hline & 27 & 20 & 84 & 165 & 19 & 76 & 73 & 110 & 42 & 10 & 11 & 23 & 22 & 9 & 18 & 32 & 20 & 11 & 28 & 35 & 17 & 31 & 16 & 9 & 236 & 77 & 13 & 11 & 14 & 265 & 23 \\
\hline & 28 & 17 & 71 & 139 & 16 & 64 & 62 & 93 & 36 & 8 & 9 & 19 & 19 & 8 & 15 & 27 & 17 & 9 & 24 & 30 & 14 & 26 & 14 & 8 & 199 & 65 & 11 & 9 & 12 & 224 & 20 \\
\hline & 29 & 21 & 88 & 172 & 19 & 79 & 76 & 115 & 44 & 10 & 12 & 24 & 23 & 10 & 19 & 33 & 21 & 11 & 29 & 36 & 18 & 32 & 17 & 9 & 246 & 81 & 13 & 11 & 15 & 277 & 24 \\
\hline & 30 & 50 & 210 & 411 & 46 & 188 & 183 & 274 & 106 & 24 & 28 & 57 & 55 & 24 & 46 & 79 & 51 & 27 & 70 & 87 & 43 & 77 & 41 & 22 & 588 & 193 & 32 & 26 & 36 & 662 & 58 \\
\hline
\end{tabular}

\section{References}

Alonso, B.; Moura, J. L.; Dell'Olio, L.; Ibeas, Á. 2011. Bus stop location under different levels of network congestion and elastic demand, Transport 26(2): 141-148.

https://doi.org/10.3846/16484142.2011.584960

Azenkot, S.; Prasain, S.; Borning, A.; Fortuna, E.; Ladner, R. E.; Wobbrock, J. O. 2011. Enhancing independence and safety for blind and deaf-blind public transit riders, in CHI'11: Proceedings of the SIGCHI Conference on Human Factors in Computing Systems, 7-12 May 2011, Vancouver, BC, Canada, 3247-3256. https://doi.org/10.1145/1978942.1979424

Biosca, O.; Spiekermann, K.; Stępniak, M. 2013. Transport accessibility at regional scale, Europa XXI 24: 5-17.

https://doi.org/10.7163/Eu21.2013.24.1

Bocarejo, J. P.; Oviedo, D. R. 2012. Transport accessibility and social inequities: a tool for identification of mobility needs and evaluation of transport investments, Journal of Transport Geography 24: 142-154.

https://doi.org/10.1016/j.jtrangeo.2011.12.004

Campbell, J. F. 1996. Hub location and the $p$-hub median problem, Operations Research 44(6): 923-935.

https://doi.org/10.1287/opre.44.6.923

Campbell, J. F. 1994. Integer programming formulations of discrete hub location problems, European Journal of Operational Research 72(2): 387-405.

https://doi.org/10.1016/0377-2217(94)90318-2

Chi, R.; Su, Y.; Qu, Z.; Chi, X. 2019. A hybridization of cuckoo search and differential evolution for the logistics distribution center location problem, Mathematical Problems in Engineering 2019: 7051248. https://doi.org/10.1155/2019/7051248

Comi, A.; Nuzzolo, A.; Brinchi, S.; Vergini, R. 2017. Bus travel time variability: some experimental evidences, Transportation Research Procedia 27: 101-108.

https://doi.org/10.1016/j.trpro.2017.12.072
Coppola, P.; Nuzzolo, A. 2011. Changing accessibility, dwelling price and the spatial distribution of socio-economic activities, Research in Transportation Economics 31(1): 63-71.

https://doi.org/10.1016/j.retrec.2010.11.009

Cordera, R.; Ibeas, Á.; Dell'Olio, L.; Alonso, B. 2017. Land Use Transport Interaction Models. CRC Press. 238 p. https://doi.org/10.1201/9780203711811

Ernst, A. T.; Krishnamoorthy, M. 1999. Solution algorithms for the capacitated single allocation hub location problem, $A n$ nals of Operations Research 86: 141-159. https://doi.org/10.1023/A:1018994432663

Gelareh, S. 2008. Hub Location Models in Public Transport Planning. Doctoral Thesis. Technical University of Kaiserslautern, Germany. 181 p. Available from Internet: https://kluedo. ub.uni-kl.de/frontdoor/index/index/docId/1949

Gelareh, S.; Nickel, S. 2011. Hub location problems in transportation networks, Transportation Research Part E: Logistics and Transportation Review 47(6): 1092-1111. https://doi.org/10.1016/j.tre.2011.04.009

Geurs, K. T.; Van Wee, B. 2004. Accessibility evaluation of landuse and transport strategies: review and research directions, Journal of Transport Geography 12(2): 127-140. https://doi.org/10.1016/j.jtrangeo.2003.10.005

Groenendijk, L.; Rezaei, J.; Correia, G. 2018. Incorporating the travellers' experience value in assessing the quality of transit nodes: a Rotterdam case study, Case Studies on Transport Policy 6(4): 564-576. https://doi.org/10.1016/j.cstp.2018.07.007

Hara, K.; Azenkot, S.; Campbell, M.; Bennett, C. L.; Le, V.; Pannella, S.; Moore, R.; Minckler, K.; Ng, R. H.; Froehlich, J. 2015. Improving public transit accessibility for blind riders by crowdsourcing bus stop landmark locations with google street view: an extended analysis, ACM Transactions on Accessible Computing 6(2): 5. https://doi.org/10.1145/2717513

Huo, Y.; Li, W.; Zhao, J.; Zhu, S. 2018. Modelling bus delay at bus stop, Transport 33(1): 12-21.

https://doi.org/10.3846/16484142.2014.1003324 
Iacono, M.; Krizek, K. J.; El-Geneidy, A. 2010. Measuring nonmotorized accessibility: issues, alternatives, and execution, Journal of Transport Geography 18(1): 133-140. https://doi.org/10.1016/j.jtrangeo.2009.02.002

Kopytkov, D.; Levchenko, O.; Rossolov, A.; Samchuk, G. 2018. Determination of the passenger transport fatigue in urban mass transportation, Komunal'ne Gospodarstvo Mist - Municipal Economy of Cities 7(146): 2-11. https://doi.org/10.33042/2522-1809-2018-7-146-2-11

Kulpa, T.; Szarata, A. 2016. Analysis of household survey sample size in trip modelling process, Transportation Research Procedia 14: 1753-1761. https://doi.org/10.1016/j.trpro.2016.05.141

Lohvinenko, V.; Rossolov, A. 2019. Evaluation of transport accessibility of the public transport network on the basis of stop points parametrization, in K. Banet (Ed.). Współczesne Pproblemy Transportu, 6-22.

Murray, A. T. 2003. A coverage model for improving public transit system accessibility and expanding access, Annals of Operations Research 123(1-4): 143-156. https://doi.org/10.1023/A:1026123329433

Naumov, V. 2019. Modeling demand for passenger transfers in the bounds of public transport network, Advances in Intelligent Systems and Computing 879: 156-163. https://doi.org/10.1007/978-3-030-02305-8_19

Nickel, S.; Schöbel, A.; Sonneborn, T. 2001. Hub location problems in urban traffic networks, Applied Optimization 48: 95107. https://doi.org/10.1007/978-1-4757-3357-0_6

Pagliara, F.; Papa, E. 2011. Urban rail systems investments: an analysis of the impacts on property values and residents' location, Journal of Transport Geography 19(2): 200-211. https://doi.org/10.1016/j.jtrangeo.2010.02.006

Papa, E.; Bertolini, L. 2015. Accessibility and transit-oriented development in European metropolitan areas, Journal of Transport Geography 47: 70-83. https://doi.org/10.1016/j.jtrangeo.2015.07.003

Rode, P.; Floater, G.; Thomopoulos, N.; Docherty, J.; Schwinger, P.; Mahendra, A.; Fang, W. 2017. Accessibility in cities: transport and urban form, in G. Meyer, S. Shaheen (Eds.). Disrupting Mobility, 239-273.

Rossolov, A. 2016. Demand modelling for public transport service based on variation of needs in travel, Transport Miejski $i$ Regionalny (7): 4-8(12).

Saghapour, T.; Moridpour, S.; Thompson, R. G. 2016. Public transport accessibility in metropolitan areas: A new approach incorporating population density, Journal of Transport Geography 54: 273-285.

https://doi.org/10.1016/j.jtrangeo.2016.06.019

Spiekermann, K.; Wegener, M.; Květoň, V.; Marada, M.; Schürmann, C.; Biosca, O.; Ulied Segui, A.; Antikainen, H.; Kotavaara, O.; Rusanen, J.; Bielańska, D.; Fiorello, D.; Komornicki, T.; Rosik, P.; Stepniak, M. 2015. TRACC: Transport Accessibility at Regional/Local Scale and Patterns in Europe. Final Report | Version 06/02/2015. Volume 2: TRACC Scientific Report. 274 p. Available from Internet: https://www.espon. eu/sites/default/files/attachments/TRACC_FR_Volume2_ScientificReport.pdf

Steinfeld, E. 2010. Universal design in mass transportation, in W. Preiser, K. Smith (Eds.). Universal Design Handbook, 19.1-19.10.

Vuchic, V. 1999. Transportation for Livable Cities. Routledge. 378 p. Yang, R.; Yan, H.; Xiong, W.; Liu, T. 2013. The study of pedestrian accessibility to rail transit stations based on KLP model, Procedia - Social and Behavioural Sciences 96: 714-722. https://doi.org/10.1016/j.sbspro.2013.08.082
Yatskiv (Jackiva), I.; Budilovich (Budiloviča), E.; Gromule, V. 2017. Accessibility to Riga public transport services for transit passengers, Procedia Engineering 187: 82-88. https://doi.org/10.1016/j.proeng.2017.04.353

Yu, B.; Yang, Z-.Z.; Jin, P.-H.; Wu, S.-H.; Yao, B.-Z. 2012. Transit route network design-maximizing direct and transfer demand density, Transportation Research Part C: Emerging Technologies 22: 58-75. https://doi.org/10.1016/j.trc.2011.12.003

Zając, A. P. 2016. City Accessible for everyone - improving accessibility of public transport using the universal design concept, Transportation Research Procedia 14: 1270-1276. https://doi.org/10.1016/j.trpro.2016.05.199

Zhang, N.; Dai, J.; Zhang, X. 2012. Walking affect area of rail transit station based on multinomial logit model, Urban Mass Transit (5): 46-49. (in Chinese). 